Shah, M., Cheng, M., \& Fitzgerald, R. (2016 online). Closing the Loop on Student Feedback: The Case of Australian and Scottish Universities. Higher Education, http://link.springer.com/article/10.1007/s10734-016-0032-x

\title{
Closing the Loop on Student Feedback: The Case of Australian and Scottish Universities
}

Mahsood Shah; Ming Cheng; Robert Fitzgerald

\begin{abstract}
Universities have a long history of collecting student feedback using surveys and other mechanisms. The last decade has witnessed a significant shift in how student feedback is systematically collected, analysed, reported, and used by governments and institutions. This shift is due to a number of factors, including changes in government policy related to quality assurance, and the increased use of the results by various stakeholders such as governments, institutions, and potential students and employers. The collection, analysis and reporting of results are systematically carried out in many institutions worldwide. However, how to use student feedback to effectively improve student learning experience remains an issue to be addressed. This paper will contribute to this debate by comparing how Australian and Scottish universities use student feedback results to inform improvements. Based on thematic analysis of external quality audit reports of all Australian and Scottish universities, this paper suggests that universities have systematic processes to collect student feedback using a range of mechanisms, but limited work is done to use the data to inform improvements. This paper argues the need for universities to genuinely listen to student voice by facilitating partnership between students and institutions to act on their feedback as part of quality assurance.
\end{abstract}

Keywords: closing the loop, student feedback, student experience, student engagement, quality assurance.

\section{Introduction}

This paper explores and compares universities' practice of closing the loop on student feedback in Australia and Scotland. Closing the loop here refers to: (1) systematic processes in communicating and sharing the results of student feedback with students, staff, and educational partners; (2) timely actions taken in partnership between institutions and students as a direct result of student voice; and (3) monitoring the effectiveness of actioned improvements. While the paper is mainly based on the practices in Australia and Scotland, it is relevant to other countries where student feedback is used as part of national and institutional quality assurance. Student feedback in this paper includes the use of standard 
national and approved institutional instruments/questionnaires aimed at gathering feedback from students on their experience. Feedback is sought to assess the quality of courses, teaching, assessments, learning resources, learning environment, and other support services.

Whilst the paper is based on the outcome of external quality audits which were undertaken more than a decade, gaps still exist in closing the feedback loop. Similarly the change in quality audit approaches in Australia from enhancement-led audits to compliance driven quality has disengaged students in internal and external quality assurance activities. Due to lack of student engagement in external quality assurance strategies at national level, there is limited innovation in institutional approaches to engage students in quality assurance. For example, despite 10 years of external quality audits, limited trend of improvement is witnessed in student experience in Australia (Shah, 2013) and Scotland (NSS, 2015). The most recent results of Student Experience Survey (SES) in Australia and the National Student Survey in Scotland reveal the need for improvement. Take Australia for example, while the quality of entire educational experience has achieved $81 \%$ satisfaction, the result shows $61 \%$ satisfaction on learner engagement and $73 \%$ satisfaction on student support. In Scotland, student overall satisfaction of the quality of their courses dropped from $88 \%$ to $85 \%$ from 2014 to 2015, of which feedback on student work is an area that achieved the lowest score 60\% (NSS, 2015). (Mahsood, there are quite a lot of data here, how about delete some of them on Australia to make it easier to read?)

The rationale behind this paper is that in many countries across the world, universities and other higher education providers are using national and institutional survey to measure the student experience. For example, in the United Kingdom, the National Student Survey (NSS) is used by governments to assess the quality of the undergraduate student experience. Similarly in the USA and Canada, the National Survey of Student Engagement (NSSE) measures the extent to which students are engaged in a variety of activities that are empirically related to desirable learning outcomes (NSSE, 2012; Price \& Baker, 2012). Based on the NSSE, a national Australasian Survey of Student Engagement (AUSSE) has been introduced for use across Australian and New Zealand universities to assess student engagement in learning (Coates \& McCormick, 2014). These survey results are used by institutions to promote their strengths and market themselves to potential students; to identify areas to be strengthened or abandoned; to recognise, reward and review academics for their contributions to teaching; and in some instances to distribute internal funding (Shah \& Nair, 2013).

However, how higher education institutions effectively use student feedback to improve learning remains an area to be explored, especially in the context of widening participation, where there is increased student diversity and expanding modes of education delivery with higher expectations by students. The effectiveness of closing the loop is also dependent on national approaches developed and sustained to engage student in quality assurance activities. In case of Australia, if national quality assurance activities does not foster and promote student partnership in quality assurance, then institutional practices fail to implement innovative mechanisms for engagement. In the UK, students are active partners in external quality assurance. The externally driven strategy has played a key role in institutional practices to engage with students. Shah \& Richardson (2015) reveals that governments have introduced policy instruments to enhance the collection, analysis, and reporting on student feedback measures and in some cases linking performance funding to 
these measures. This is evidenced in that Australian and the UK governments are now publishing student feedback results in the public domain to increase transparency and accountability (Shah \& Nair, 2012). Meanwhile institutions are increasingly using ranking and league tables as a measure of quality. The website RateMyProfessor.com in the US is increasingly used to rate 1.4 million professors and over 7,000 schools (Blaske-Rechek \& Kelsey, 2010). Making these results and other data publicly available allows students and other stakeholders to make informed choices on where to study. However, there is lack of evidence of good engagement of staff and students in communicating the national survey feedback results and in taking actions for improvement, despite this being an important strategy for improving response rates and identifying areas for improvement (Grebennikov \& Shah, 2013a).

This paper argues the need to develop innovative ways to engage students and student unions in quality assurance and enhancements, particularly as the dynamic of higher education landscape changes with increased debate on university funding. In the Australian context, university led initiatives to engage students in quality assurance activities is shifting focus due to the compliance driven quality and regulatory regimen oversighted by the Tertiary Education Quality and Standards Agency (TEQSA). TEQSA's approach to quality assessment in re-accreditation of universities and private higher education providers does not engage students and student unions on their views about the quality of teaching, learning, research, or on the quality of on and off-campus support (Shah et al. 2014). In contrast, in the UK and particularly in Scotland, strategies are in place to directly engage students around these issues of quality assurance. They include the use of student reviewers in external reviews by the Quality Assurance Agency (QAA); and formation of Student Participation in Quality Scotland (SPARQS) which is funded by the Scottish Funding Council to assist and support students, students' associations and institutions in improving the effectiveness and engagement in quality assurance and enhancement (Shah et al. 2014). However, to date, there is limited study on how the results of student feedback have been consistently used in both countries to improve the student learning experience.

\section{Previous Research}

This paper considers that literature on the measurement and enhancement of student experience is wide and varied. It ranges from the power of feedback in teaching and learning (Hattie \& Timperley, 2007; Tucker, 2013a), to the diversity of the experience of various cohorts of students (Brown, 2011; Grebennikov \& Shah, 2012; James et al. 2010; Tucker, 2013b), the importance of the first year experience (James et al. 2010; Kift et al. 2010), the need for effective student engagement (Coates, 2005; Krause \& Coates, 2008), and the positive correlation between satisfaction, student retention (Scott, 2006) and grades (Tucker et al. 2012). Further there is a link between student satisfaction and student feedback, such that there are good predictors of both high and low satisfaction (Grebennikov \& Skaines, 2009; Scott, 2006; Kane et al, 2008) and the strategies deployed to improve student satisfaction (Grebennikov \& Shah, 2013a; Leckey \& Neill, 2001; Nelson, Smith, \& Clarke, 2012; Pitkethly \& Prosser, 2001); and methodology and its impact on response rates and satisfaction (Moskal et al. 2015; Bennett \& Nair, 2010; Dommeyer et al. 2004; Nair \& Adams, 2009; Nair, Adams, Ferraiuolo, \& Curtis, 2009; Nowell et al. 2010; Stowell et al. 2011;).

Despite the considerable research outlined previously, very little is known about the practices adopted by higher education institutions to systematically use student feedback in 
renewing curriculum, enhancing teaching, assessments, and improving the student experience (Ballantyne, Borthwick \& Packer, 2000; Tucker, 2013 a, b; Van Os, 2010). A few studies in Australia and overseas suggest that if students do not see course/unit improvements arising from their feedback, they are less likely to participate in future surveys (Leckey \& Neill, 2001; Nair et al. 2010; Powney \& Hall, 1998; Shah \& Nair, 2009; Symons, 2006; Watson, 2003). This failure to close the feedback loop creates a climate in which students do not take feedback mechanisms seriously, and can result in students using the opportunity to vent their frustration, rather than providing constructive feedback (Tucker et al., 2008). Khan's (2013) study of students' views about feedback in United Arab Emirates reveals that students only provide honest feedback if they perceive timely actions are taken. Williams and Brennan (2003) warn of the very real danger that "student cynicism may endanger the potentially very valuable functions that student feedback data can perform" (p.71).

The importance of understanding the student feedback loop was also highlighted as an area for improvement in the analysis conducted by Christine Ewan as part of a study commissioned by Carrick Institute of Learning and Teaching (now Office for Learning and Teaching) and the Australian Universities Quality Agency (AUQA) (Carrick Institute for Learning and Teaching, 2005). In Australia, TEQSA's standards require higher education institutions to demonstrate how student feedback is used and how the results and actions are communicated to students (TEQSA, 2012, p. 31). However, the extent to which this is assessed and monitored by TEQSA in institutional quality assessments is not entirely clear. In the UK, the QAA has developed a quality code related to student engagement. All higher education institutions are required to meet the requirements of the code which is part of institutional quality audits (QAA, 2012). Student surveys have become an influential source of information for a range of stakeholders both in its own right and through its impact on league tables (HEFCE, 2008). However, there is more work to be done here as a recent study in the UK found that only one out of the ten institutions surveyed fed student survey results and actions back to students (Electric Paper Ltd, 2014).

Previous studies have shown that if universities do not systematically close the loop on student feedback then there are manifold risks including declining response rates, poor student engagement in feedback process, and lack of trust between universities, students, and academics on improvements as a result of their voice (Khan, 2013; Leckey \& Neill, 2001; Nair et al. 2010; Powney \& Hall, 1998; Shah \& Nair, 2009; Symons, 2006; Tucker et al.; 2008; Watson, 2003; Williams \& Brennan, 2003). Failing to close the loop on feedback questions the quality assurance framework in institutions and the extent to which they are used to enhance educational quality.

The aim of this study was to compare the relevant quality assurance practice of Australian and Scottish universities in order to extend the understandings of how student feedback results have been used to improve student learning. These two countries were selected because quality audits in both emphasize the enhancement of student experience, and the Scottish university sector in particular has been regarded as world leading in the management of academic quality.

\section{Methodology}


For Australia, this study involved a thematic analysis of the Australian Universities Quality Agency (AUQA) cycle 1 audits of all 39 universities between 2001-2008 and cycle 2 audits of 32 universities between 2009-2012. In both cycles of audits, the audit panel focused on issues related to student feedback, student experience, and the role of students in quality assurance. In total 71 Australian university reports were analyzed. For Scotland, this study involved the thematic analysis of 29 universities' Enhancement-led Institutional Review (ELIR) reports between 2004 and 2012. The ELIR operates on a five- year cycle and it is undertaken by the QAA for Higher Education on behalf of the Scottish Funding Council. The ELIR focuses on an institution's enhancement strategies and the arrangements for improving student learning experience (QAA, 2015).

In both countries external quality agencies funded by the government conduct audits. As part of the audit process, institutions submit the self-review portfolio and a panel of external reviewers are selected to conduct audits. The audit involves review of self-review portfolio and interviews with a range of stakeholders such as senior management, teaching and support staff, students, alumni, employers, and staff and student unions. Where relevant the panel also interviews offshore partners, students, and staff. The panel concludes the findings based on information collected from audit visit and other institutional performance data, and the reports are published online with open access.

The full report of all Australian and Scottish Universities was carefully read and analysed by the authors. These reports are published online for public access, so there are no issues of confidentiality and anonymity to use the text for this research. Keywords such as student experience, student feedback, student voice, student engagement, and closing the loop on feedback were searched in each audit reports. All quotes related to these keywords were identified and coded by Nvivo software. Nvivo was selected as it maximises the extent to which the qualitative data can be analysed in a rigorous and transparent way (Cresswell, 2013). Recurring themes were analysed and categorized as engaging staff and engaging students.

\section{Findings}

Despite decades of using student surveys as part of national and institutional quality assessment in Australia and Scotland, there were significant gaps in student feedback processes. The key gap was related to the unsystematic use of student feedback by autonomous academics in changing curriculum design, teaching methods, assessment, and student services (both academic and non-academic). All universities $(n=68)$ in both countries had been actively participating in international, national, and institutional surveys. Surveys such as International Student Barometer, NSS in the UK which is similar to the Course Experience Questionnaire (CEQ) in Australia, and end of semester evaluations were used in both countries. The self-review report which institutions presented to quality agencies, such as QAA and AUQA, provided the results of various surveys. The audit findings in both countries highlighted that there is limited work in: (1) systematically addressing areas that need improvement as a direct result of student feedback, (2) sharing the results of the survey with students and partner institutions, (3) communicating the actions taken by the university as a direct result of student survey results. Based on the analysis of the audit reports, this section outlines the key findings which suggest that closing the loop can be categorised in two types: engaging students, and engaging staff. The recurring themes are presented under the two types. 


\section{Closing the loop: Type 1: Engaging Students}

Various stakeholders are involved in student feedback process. They include management of the university, key academic leaders (e.g. associate deans, discipline heads, course and unit coordinators), academic and professional staff, and partner institutions delivering joint courses, students, and student unions. Different stakeholders have their own priorities. Senior management may not be able to address all areas of concern due to resource constraints. Likewise academic leaders at faculty and school level may have competing priorities related to course reviews, course accreditation, and new curriculum design. Individual academics at times may be offended by some feedback from students on quality of teaching, overall coordination, and issues around assessments. On the other hand students as key stakeholders expect that their feedback is valued and improvements are implemented in a timely manner. Most areas of improvement related to curriculum changes, teaching quality, and assessments require formal process and approvals before changes are implemented. The process of acting on student feedback could be worse in large universities with multi-campus and multi-mode education delivery.

In recognising the complexity involved, the authors describe closing the loop as two types: engaging students and engaging staff. "Closing the loop - engaging students" involves informing students about the survey results and communicating the planned actions or actions that maybe underway. Institutions may communicate the summary of the findings and point students to the full report and planned actions that maybe underway. In this regard few Australian and Scottish universities are well underway and the practice is patchy in both countries. Only seven institutions were commended for systematically using student survey data and closing the loop. For example in Australia, the audit panel commended the University of Technology, Sydney (UTS) for (a) its commitment to monitoring student satisfaction with services relevant to their overall experience of UTS and (b) for acting on student feedback (UTS, 2006, p. 38).

At Curtin University in Australia, the audit panel was convinced that the university has systematic process for collection, analysis, reporting, and communicating the result of end of semester evaluations with all students. The panel found consistency in the use of the survey and actions taken at both Australian and overseas campuses. Extracts from the audit report state: the panel is able to confirm the positive impact which the eVALUate unit survey is having on learning and teaching. All campuses in Australia and at Sarawak use the survey and it is also being used by Curtin students in partner institutions. As already noted, students can track reports and improvements on the eVALUate website (Curtin, 2009, p. 14). In Scotland, similar findings apply to the Robert-Gordon University where the audit found that the University seeks to inform its students of the outcomes resulting from the feedback they provide in a number of ways, including making available on the Student Portal the statistical results of module and course evaluation questionnaires, and posting the outcomes of meetings with students on the Student Involvement @ RGU website (QAA, 2007a, p. 16).

In Scotland, there was limited evidence that systematic work had been carried out by universities to effectively use student feedback to improve the student learning experience, in spite of the majority of universities having taken steps to improve the feedback mechanisms. For example, the University of Edinburgh Napier identified the 'feedback loop' as one of six key areas of enhancement activity in its Student Involvement in Learning, Teaching and Assessment project (QAA, 2011b). Other examples include the Robert 
Gordon University which changed its questionnaire system to an electronic platform and obtained further student feedback through the use of focus groups (QAA, 2007a). In other examples, universities in Scotland have responded to student feedback in relation to assessment tasks. The growing of students on marking of assessment tasks and quality of feedback resulted the University of Stirling and Heriot Watt to develop a Code of Practice on student feedback to clarify the University's expectations regarding assessment tasks and feedback for both staff and students (QAA, 2010a) and to establish a set of minimum requirements to ensure coherence and equity (QAA, 2006a). These codes were developed in response to student feedback in relation to assessments. Similarly the University of St Andrews undertook a strategic review of feedback mechanisms, and developed and approved a policy Feedback to Students on Work Submitted for Assessment in 2009 to provide guidelines on assessment feedback (QAA, 2011c). The University of West of Scotland produced a very practical outcome in the form of an Assessment Handbook for staff, aiming at achieving consistency in their provision of feedback to students on their assessed work (QAA, 2011d).

\section{Limited or no improvements despite student feedback}

In many institutional audits in Australia and Scotland, the panel found that students often see limited or no improvements despite providing feedback. At the University of Adelaide, Australia, the panel commented that many students reported their perception that the evaluations may not be taken seriously by staff and that they were not made aware of any changes made to courses as a result of their feedback (Adelaide, 2003, p.48). At James Cook University (JCU) the panel stated that there is no strong evidence of action being taken in response to student feedback on subjects (TEQSA, 2011, p. 41). At Notre Dame University, Australia students reported that they are not clear or are insufficiently informed about what happens as a result of their many and regular completed questionnaires on teaching and unit feedback. Similarly in Scotland, the audit of Edinburgh Napier University revealed that it is not always clear how the results of the student surveys are being used at an institutional level to inform policy changes which seek to enhance the student experience (QAA, 2006b, p. 14). The audit of the University of Aberdeen also reported a lack of feedback that students receive on actions taken to address their concerns (QAA, 2010b, $p$. 12).

In these audit reports, many institutions recognised the need to communicate the results with students; however the rhetoric does not match the reality. While some universities in Scotland had taken positive steps the overall impact had been small. Similarly at the Royal Melbourne Institute of Technology (RMIT) in Australia the panel found significant effort in collection, analysis, and reporting on survey results, but limited work being undertaken on improvements. The audit report stated student frustration with what they perceive as inadequate actions taken as a result of their comments suggests that greater attention may be needed - both to the responses themselves and to advising students of the actions taken and the panel suggests that strategies to achieve this should be particularly considered in the current review (RMIT, 2003, p.39).

\section{Need to engage students more fully in quality assurance}

The engagement of students in quality assurance is an area needing improvement in Australian universities. Various audit reports in Australia suggest the need to explore new 
forms of partnership with students. The current practices in many Australia to engage students are through formal feedback and membership in committee such as academic board/senate. Despite the presence of external and internal quality assurance mechanisms, there is lack of policies and initiatives that enable partnership between universities and students unions. For example, the audit of the University of Queensland (UQ) found that students are somewhat sceptical about the value of these evaluation tools. They do not see the loop closed in the sense of being made aware of changes that have occurred as a result of student feedback, and indeed sometimes the loop is not closed. There is a need to better explore ways of linking data and outcomes and communicating the latter to students (UQ, 2003, p.27). The findings at UQ is also found in previous studies by Leckey and Neill (2001) who argue that if students do not see any action resulting from their feedback, they may become sceptical and unwilling to participate. Student willingness to see change as a result of feedback was also evident in the audit report of the University of Melbourne (UMelb). The panel found that there was a general agreement among the students that it is difficult to maintain enthusiasm to continue to fill out the questionnaires if there is little evidence that they have an effect. A large proportion of the students also expressed a wish to get direct feedback from the teachers on the initiatives and amendments resulting from the surveys (UMelb, 2006, p. 28).

In contrast, the audit findings in Scottish Universities highly praised institutions on various mechanisms that are in place to engage students in institutional governance and quality assurance. Various initiatives are in place such as: student-staff liaison committees; student member in internal programme and school review panels; training for students in various committees; handbook and briefing for student representatives; mechanisms to engage students in informal feedback on their experience; focus groups and advisory activities; partnership between university and student associations, and many others. For example, the audit of the University of Strathclyde found that both the University and student association identify the quality of their interrelationship as one of the institution's 'great strengths' (QAA, 2005 , p. 43). Similarly in the University of Robert Gordon the audit found that student representation on boards and committees had positively impacted on the work of these bodies by providing a more clearly student-focused emphasis and insight, and through students' abilities to 'truly represent the wider community' (QAA, 2007a, p. 14).

\section{The experience of offshore students is not well understood}

The issues raised above are mostly focused on face-to-face teaching modes involving onshore students. A few audit reports have highlighted the significant gaps in closing the feedback loop with students studying at transnational campuses or with partner institutions. The audit report of Macquarie University (MU) in Australia stated that interviews with staff revealed that there is no sharing of the results of either student evaluation of teaching or of course data between an transnational partner and Macquarie University (MU, 2003, p.40). Transnational education students confirmed that they complete evaluation forms, but are generally not informed about how the student feedback was used to improve the quality of provision (MU, 2009, p.34). At the University of South Australia (UniSA) the audit found poor survey response rates in transnational education and generally a lack of closing the feedback loop with transnational students. The panel found that there was a near unanimous view amongst those interviewed that transnational students were not aware of any outcomes as a result of responses to their feedback (UniSA, 2009, p.23). 
In one Scottish University, the audit found concerns on the extent to which improvements are implemented in relation to courses taught in flexible and distance mode. The panel raised concerns relating to students feedback arrangements for distance and distributed learning students (Heriot-Watt University, 2006, p.39). Similarly, in one Australia institution where courses are offered at a distance often brokered by education agents, the audit found that Student Evaluation of Teaching surveys are used for every distance education course, but the agents (and the students) do not see the results. In turn, some agents conduct surveys of the course, teaching and facilities, but do not share this information with University of Southern Queensland (USQ). While there is a recognised division of labour involved and the purpose of evaluations can differ, there is some duplication (USQ, 2002, p.20).

\section{Closing the loop: Type 2: Engaging Staff}

The second type of closing the loop is described as "Closing the loop-engaging staff". This type places accountability on key academic leaders to review the results of the survey and implement changes. The process of informing students on what the university is planning to do is simple. It requires identifying areas needing improvement and seeking approval from senior staff if improvements require resourcing. However, promising improvements without delivering results could do more damage than gaining trust. Throughout 3-4 year of study, an undergraduate student would have been invited or completed more than 60 surveys. This includes end of semester evaluations of units, teacher(s) and tutor(s), course experience surveys, and other national and institutional surveys. In many instances student may repeatedly raise concern on similar issues (e.g. timely feedback on assessment, quality of teaching), but they may not have seen any change throughout the learning journey. The challenge for key academic leaders such as associate deans is to work with discipline heads and course coordinators to review the results of the survey at course and unit of study level to identify areas of good practice and areas needing improvement. Some of the planned changes such as curriculum redesign, assessment methods, and teaching quality may create angst, but such improvements are needed with increased use of student voice to measure educational quality. It could be argued that improvements in campus facilities and services are relatively straight forward areas that could be developed to improve the student experience. However, changes in curriculum content, assessment and pedagogy require the more complex engagement of the various stakeholders.

In Australia, some audit reports stressed the importance of academic staff using and acting on end of semester evaluations. The report of La Trobe University stated that University needs to promote greater use of its Student Evaluation of Teaching survey, but particularly so that more staff will seek and act upon student feedback on their teaching through a system that may provide for benchmarking and professional support (La Trobe, 2005, p. 27).

\section{Discussion}

There is no doubt that student experience measures will continue to be used at national and institutional level to measure quality. Results of such surveys are available in public domain for prospective students to make informed choices. While there is no sign of linking funding against student experience measures, the QILT in Australia and Teaching Excellence Framework (Department for Business Innovation \& Skills, 2015) in the UK could be used to reward universities. Universities in various countries are using student experience measures 
to assess academic staff as part of annual performance review process. However, increased use of such measures could punish staff, if scores are below university or faculty average.

One could question whether students with no or limited experience in curriculum design and pedagogy, assessments, and teaching methods are legitimate stakeholders in changing academic practices, especially where those practices are informed by sound scholarly research. Historically, academic have strongly argued about their autonomy, however this trend is changing. The marketization of higher education is providing more autonomy to students to raise voice and concern using channels such as social media, google reviews, and formal complaints to government funded agencies. If the academy believes that students are not the legitimate stakeholders in changing curriculum and pedagogy, then one needs to question the role of student feedback and the extent to which it should be used in changing academic practice such as assessment standards.

There is evidence that institutions are increasingly using student feedback results in the performance reviews of academic staff. Many scholars have written about student feedback and evaluations. Limited case studies of good practice are published on how feedback from national surveys is systematically used by autonomous academics to revise curriculum content, assessments design, and teaching methods in a timely manner. Often the result of feedback (e.g. student evaluations and CEQ) is lagging when students have either completed the study and left the University or moved to the next teaching period.

Scholars have argued that there is a danger of relying on student satisfaction to assess educational quality (Williams, de Rassenfosse, Jensen \& Marginson, 2013). Kirk \& Miller (1986) remind us that getting the question wrong is the main threat to the validity of our measurements. However, even if we have the right questions there are still risks that the "tail wags the dog". That is, an over reliance on simple metrics, such as student satisfaction measures, can result in perverse outcomes where teaching practices can be driven by student's "happiness" and result in practices that are inconsistent with contemporary educational theory and practice (Hattie \& Yates, 2014; Miller \& Seldin, 2014). This problem is further exacerbated when teaching evaluations results are used in academic staff performance reviews. Research has shown that even small, statistically insignificant declines in student satisfaction can impact negatively on reviews of academic performance (Boysen, Kelly, Raesly, \& Casner, 2014).

\section{Conclusion}

The findings clearly suggest that closing the feedback loop is an area needing improvement in both Australia and Scotland. Universities in both countries have systematic processes to collect, analyze and report student survey results, but there is limited evidence of effective use of student feedback to improve student learning experience. Scottish Universities have made good progress in engaging students in quality assurance and other activities, which is evidenced in the partnership between universities, students and student unions.

However, students have expressed in the audit report that they saw limited improvement despite providing feedback. The results of student surveys are increasingly used on public websites such as Unistats in the UK, and QILT in Australia and often find their way into the public arena through the media. Not only are institutional reputations at risk and but also their futures, as made clear by Richard Levin, former president of Yale University and 
current CEO of Coursera, who said, "In 10 or 20 years, when we judge the great universities, it will not just be on their research but on the reach of their teaching" (The Chronicle of Higher Education, 2014). The global reach of teaching and its reputation using flexible mode can only be achieved if students have positive learning experience.

Australian and Scottish universities are experiencing low response rates in student surveys and other institutions across the world share similar concerns (Adams \& Umbach, 2012; Smithson et al, 2015). The low response rates have implications for both universities and students. It can be seen as an indicator of student disengagement with surveys and feedback, which needs to be examined. Innovative ways therefore need to be developed and deployed by universities to capture student voice, because students as fee payers are increasingly demanding that their views need to be heard and acted upon (Williams, 2002).

Furthermore, student disengagement in surveys could also be due to survey fatigue with many formal surveys conducted as part of quality assurance and informal surveys being conducted by individuals for different purposes. For example, teacher and unit evaluations are often undertaken either in the mid or end of the semester and data is analysed and reported before or during the next teaching period. The students who have completed the unit of study will rarely see changes in that specific unit of study. More developmental forms of evaluation need to be developed. For example, academics undertaking regular design/focus group type interviews with students would help generate timely feedback which could be fed back to teaching teams to support continuous unit improvements. Students studying in the unit would be able to contribute to and see the changes to the unit as it evolves. Adopting a more continuous improvement approach to university teaching could result in benefits for students and teachers alike. Adopting more team-based approaches to unit improvement would reduce help overcome this challenge. 


\section{References}

Adams, M. J. D. \& Umbach, P. D (2012). Nonresponse and online student evaluations of teaching: Understanding the influence of salience, fatigue, and academic environments. Research in High Education, 53(5):1-16.

Australian Universities Quality Agency. (2002). Report of an Audit of Australian Catholic University, Melbourne, Australia.

Australian Universities Quality Agency. (2006). Report of an Audit of the University of Technology, Sydney, Melbourne, Australia.

Australian Universities Quality Agency. (2009). Report of an Audit of the Curtin University of Technology, Sydney, Melbourne, Australia.

Australian Universities Quality Agency. (2005). Report of an Audit of the University of Tasmania, Melbourne, Australia.

Australian Universities Quality Agency. (2003). Report of an Audit of the University of Adelaide, Melbourne, Australia.

Australian Universities Quality Agency. (2003). Report of an Audit of the University of Notre Dame, Melbourne, Australia.

Australian Universities Quality Agency. (2003). Report of an Audit of RMIT University, Melbourne, Australia.

Australian Universities Quality Agency. (2005). Report of an Audit of La Trobe University, Melbourne, Australia.

Australian Universities Quality Agency. (2011). Report of an Audit of Charles Darwin University, Melbourne, Australia.

Australian Universities Quality Agency. (2004). Report of an Audit of Charles Sturt University, Melbourne, Australia.

Australian Universities Quality Agency. (2006). Report of an Audit of Flinders University, Melbourne, Australia.

Australian Universities Quality Agency. (2009). Report of an Audit of the University of Western Australia, Melbourne, Australia.

Australian Universities Quality Agency. (2003). Report of an Audit of the University of Queensland Australia, Melbourne, Australia.

Australian Universities Quality Agency. (2006). Report of an Audit of the University of Melbourne Melbourne, Australia.

Australian Universities Quality Agency. (2006). Report of an Audit of Macquarie University, Melbourne, Australia.

Australian Universities Quality Agency. (2009). Report of an Audit of University of South Australia, Melbourne, Australia.

Australian Universities Quality Agency. (2006). Report of an Audit of the University of Melbourne Melbourne, Australia.

Ballantyne, R. Borthwick, J. \& Packer, J. (2000) Beyond Student Evaluation of Teaching: Identifying and addressing academic staff development needs, Assessment \& Evaluation in Higher Education, 25, 3, 221-236.

Bennett, L., \& Nair, S. (2010). A recipe for effective participation rates for web-based surveys. Assessment and Evaluation in Higher Education, 35 (4), 357-365.

Billot, J. Hallas \& E. Whitehead (Eds.), 36th HERDSA Annual International Conference (pp. 470-484). Auckland, New Zealand: Research and Development in Higher Education: The Place of Learning and Teaching. Retrieved from http://www.herdsa.org.au/?page id=3502

Blaske-Rechek, A., and M. Kelsey. 2010. Ratemyprofessor.com: Testing Assumptions about Student Use and Misuse. Practical Assessment, Research \& Evaluation 15 (5): $1-12$.

Accessed August 2013. http://pareonline.net/pdf/v15n5.pdf

Boysen, G. A., Kelly, T. J., Raesly, H. N., \& Casner, R. W. (2014). The (mis)interpretation of teaching evaluations by college faculty and administrators. Assessment \& Evaluation in Higher Education, 39(6), 641-656. doi: 10.1080/02602938.2013.860950 
Brown, S. (2011). Bringing about positive change in the higher education student experience: A case study. Quality Assurance in Education, 19(3), 195-207.

Brown, T., \& Katz, B. (2009). Change by design: How design thinking transforms organizations and inspires innovation. New York: Harper Collins.

Carrick Institute for Learning \& Teaching in Higher Education, (2005). Promoting and Advancing Learning \& Teaching in Higher Education: The messages from AUQA reports.

Coates, H. (2005). The value of student engagement for higher education quality assurance, Quality in Higher Education, 11 (1), 25-36.

Coates, H., \& McCormick, A. (2014). Engaging university students: International insights from system wide studies. Springer, London, UK.

Cresswell, J.W. (2013). Qualitative inquiry and research design: Choosing among five approaches. Sage, London, UK.

Dommeyer, C. J., Baum, P., Hanna, R. W., \& Chapman, K. S. (2004). Gathering faculty teaching evaluations by in-class and online surveys: Their effects on response rates and evaluations. Assessment and Evaluation in Higher Education, 29(5), 611-623.

Dunne, D., \& Martin, R. (2006). Design thinking and how it will change management education: An interview and discussion. Academy of Management Learning \& Education, 5(4), 512-523.

Electric Paper Ltd. (2014). Closing the loop: Are universities doing enough to act on student feedback from course evaluation surveys?

Grebennikov, L., \& Shah, M. (2012). Commencing Student Experience: New Insights and Implications for Action. European Journal of Higher Education, 2(2-3), 267-289

Grebennikov, L., \& Shah, M. $\left(2013^{a}\right)$. Trends in Monitoring Student Satisfaction. Tertiary Education Management, 19 (4), 301-322.

Grebennikov, L., \& Shah, M. (2013 $)$. The Student Voice: Using Qualitative Student Feedback to Enhance the Student Experience. Teaching in Higher Education, 18 (6), 606-618.

Grebennikov, L., \& Skaines, I. (2009). University of Western Sydney students at risk: Profile and opportunities for change. Journal of Institutional Research 14(1), 58-70.

Hattie, J. \& Timperley, H. (2007). The Power of Feedback, Review of Educational Research, 77 (1), 81-112.

Hattie, J., \& Yates, G. (2014). Visible learning and the science of how we learn. New York: Routledge.

Higher Education Funding Council for England. (2008). Counting what is measured or measuring what counts? League tables and their impact on higher education institutions in England.

James, R., Krause, L. K. \& Jennings, C. (2010). The First Year Experience in Australian Universities: Findings from 1994 to 2009, Centre for the Study of Higher Education, The University of Melbourne, available at: http://www.cshe.unimelb.edu.au/research/experience/docs/FYE_Report_1994_to_2009. $p d f$

Kane, D., Williams, J., \& Cappuccino-Ansfield, G. (2008). Student Satisfaction Surveys: The Value in Taking a Historical Perspective, Quality in Higher Education, 14 (2), 135155.

Khan, M. (2013). Evaluation of Course Evaluations: Views from Students, Staff and Seniors Management. In M. Shah \& C. S. Nair (Eds.), CAA Quality Series No. 5 (Vol. June, pp. 16-33). Abu Dhabi: Ministry of Higher Education and Scientific Research. Available at: https://www.caa.ae/caa/desktopmodules/qualityseries.aspx

Kift, S., Nelson, K. \& Clarke, J. (2010). Transition pedagogy: A third generation approach to FYE - A case study, The International Journal of the First Year in Higher Education, 1(1), 1-20.

Kirk, J., \& Miller, M.L. (1986). Reliability and validity in qualitative research. Beverly Hills, 
CA: Sage Publications.

Kolowich, S. (2014). Coursera Chief: Reach of Teaching Will Define Great Universities, The Chronicle of Higher Education, 19 June. Available at http://chronicle.com/blogs/wiredcampus/coursera-chief-reach-of-teaching-will-definegreat-universities $/ 53445$

Krause, L. K. \& Coates, H. (2008). Students' engagement in first-year university, Assessment and Evaluation in Higher Education, 33 (5), 493-505.

Leckey, J., \& Neill, N. (2001). Quantifying quality: The importance of student feedback. Quality in Higher Education, 7 (1), 19-32.

Miller, J. E., \& Seldin, P. (2014). Changing practices in faculty evaluation. Washington: American Association of University Professors.

Moskal, C.M.A., Stein, J.S., \& Golding, C. (2015). Can you increase teacher engagement with evaluation simply by improving the evaluation system?, Assessment \& Evaluation in Higher Education, DOI: 10.1080/02602938.2015.1007838.

Nair, C. S., \& Adams, P. (2009). Survey platform - a factor influencing online survey delivery and response rate. Quality in Higher Education, 15 (3), 291-296.

Nair, C. S., Adams, P., Ferraiuolo, S., \& Curtis, A. (2009). Survey platform influences delivery and response rate? In C. S. Nair (Ed.), Evidence based decision making: Scholarship and practice (pp. 66-72). Melbourne, VIC: Monash University.

Nair, C.S., Mertova, P. \& Pawley, D. (2010). Quality in Action: Closing the Loop. Quality Assurance in Education 18 (2), 144-155.

National Student Survey. (2015). Available at: http://www.hefce.ac.uk/tt/nss/results/2015/

National Survey of Student Engagement. (2012). About NSSE. Available at: http://nsse.iub.edu/html/about.cfm

Nelson, K. J., Smith, J. E., \& Clarke, J. A. (2012). Enhancing the transition of commencing students into university: An institution-wide approach. Higher Education Research \& Development, 31 (2), 185-199.

Nowell, C., Gale, R. Lewis., \& Handley, B. (2010), Assessing faculty performance using student evaluations of teaching in an uncontrolled setting, Assessment and Evaluation in Higher Education, 35 (4), 463-475.

Pitkethly, A., \& Prosser, M. (2001). The first-year experience project: A model for university- wide change. Higher Education Research and Development, 20 (2), 185198.

Powney, J., \& Hall, S. (1998). Closing the loop: The impact of student feedback on students' subsequent learning. Glasgow: The Scottish Council for Research in Education, University of Glasgow.

Price, K., \& Baker, N, S. (2012). Measuring Students' Engagement on College Campuses:

Is the NSSE an Appropriate Measure of Adult Students' Engagement?, The Journal of Continuing Higher Education, 60(1), 20-32.

Quality Assurance Agency for Higher Education. (2012). UK Quality Code for Higher Education Part B: Assuring the enhancing academic quality: Chapter B5: Student engagement. Available at: http://www.qaa.ac.uk/assuring-standards-andquality/the- quality-code/quality-code-part-b

Quality Assurance Agency for Higher Education. (2005). Enhancement-led institutional review: University of Strathclye, UK.

Quality Assurance Agency for Higher Education. (2006a). Enhancement-led institutional review: University of Heriot-Watt, UK.

Quality Assurance Agency for Higher Education. (2006b). Enhancement-led institutional review: Edinburgh Napier University, UK.

Quality Assurance Agency for Higher Education. (2007a). Enhancement-led institutional review: The University of Robert Gordon, UK.

Quality Assurance Agency for Higher Education. (2009). Learning from ELIR 
2003-07: Emerging approaches to student engagement in quality assurance and Enhancement. Available

at: http://dera.ioe.ac.uk/448/2/StudentEngage08.pdf

Quality Assurance Agency for Higher Education. (2010a). Enhancement-led Institutional Review: University of Stirling, UK.

Quality Assurance Agency for Higher Education. (2010b). Enhancement-led Institutional Review: University of Aberdeen, UK.

Quality Assurance Agency for Higher Education. (2011b). Enhancement-led Institutional Review: Edinburgh Napier University, UK.

Quality Assurance Agency for Higher Education. (2011c). Enhancement-led Institutional Review: University of St Andrews, UK.

Quality Assurance Agency for Higher Education. (2011d). Enhancement-led Institutional Review: University of West of Scotland, UK.

Quality Assurance Agency for Higher Education. (2011e). Enhancement-led Institutional Review: Edinburgh Napier University, UK.

Quality Assurance Agency for Higher Education. (2011f). Enhancement-led Institutional Review: University of Heriot-Watt, UK.

Quality Assurance Agency for Higher Education. (2012). Enhancement-led Institutional Review: University of Abertay Dundee, UK.

Quality Assurance Agency for Higher Education. (2015). Learning from ELIR 200811. Available at: http://www.qaa.ac.uk/en/Publications/Documents/Learningfrom-ELIR- Student-representation.pdf

Quality Assurance Agency for Higher Education. (2015). Enhancement-led Institutional Review. Available at: http://www.qaa.ac.uk/reviews-and-reports/how-we-review-higher education/enhancement- led-institutional-review

Scott, G. (2006). Accessing the student voice: Using CEQuery to identify what retains students and promotes engagement in productive learning in Australian higher education. Canberra, ACT: DEST. Available at: http://www.dest.gov.au/sectors/higher_education/publications_resources/profiles/access student_voice.htm

Shāh, M. (2012). Ten Years of External Quality Audit in Australia: Have Audits Improved Quality Assurance in Universities? Assessment and Evaluation in Higher Education, 37 (6), 761-772.

Shah, M., \& Nair, S. C. (2012). The Changing Nature of Teaching Evaluations in Australian Universities. Quality Assurance in Education, 20 (3), 274-288.

Shah. M., \& Nair, S. (2013). Enhancing Student Feedback and Improvement Systems in Tertiary Education, CAA Occassional series 5, Commission of Academic Accreditation (CAA), United Arab Emirates (UAE).

Shah, M., \& Nair C. S. (2009). Using student voice to improve student satisfaction: Two Australian universities - the same agenda. Journal of Institutional Research (South East Asia), 7 (2), 43-55.

Shah, M., Hartman, K., \& Hastings, G. (2014). Partners or Opponents: The Engagement of Students in a Compliance Driven Quality Assessment. Perspectives: Policy and Practice in Higher Education, 18 (1), 20-28.

Shah, M., \& Richardson, E. T. J. (2015). Is the Enhancement of Student Experience a Strategic Priority in Australian Universities?, Higher Education Research and Development (HERD), DOI:10.1080/07294360.2015.1087385.

Smithson, J., Birks, M., Harrison, G., Sid Nair, C., \& Hitchins, M. (2015). Benchmarking for the effective use of student evaluation data. Quality Assurance in Education, 23(1): 20 $-29$.

Stowell, R. J., Addison, E. W., \& Smith, L. J. (2011), "Comparison of online and classroombased student evaluations of instructions", Assessment and Evaluation in Higher Education, pp. 1-9.

Symons, R. (2006). Listening to the student voice at the University of Sydney: Closing the 
loop in the quality enhancement and improvement cycle. Paper presented at the 2006 Australian Association for Institutional Research Forum, Coffs Harbour, NSW, 21-24 November.

Tertiary Education Quality and Standards Agency (TEQSA). (2012). Application for registration as a higher education provider. Available at http://www.teqsa.gov.au/sites/default/files/GuidelnitialRegistration.pdf

Tertiary Education Quality and Standards Agency. (2011). Report of an Audit of James Cook University, Melbourne, Australia.

Tucker, B. (2013a). Development of a student evaluation quality culture: The eVALUate experience at Curtin. Enhancing student feedback and improvement systems in tertiary education, June(CAA Quality Series No. 5), 16-33.

Tucker, B. (2013b). Student evaluation to improve the student learning experience: An Australian university case study. Educational Research and Evaluation, 19(7), 615-627.

Tucker, B., Pegden, J., \& Yorke, J. (2012). Outcomes and evaluations: Is there a relationship between indicators of student success and student evaluations of learning? In N. Brown,

S. M. Jones \& A. Adam (Eds.), 35th HERDSA Annual International Conference. Research and Development in Higher Education: Connections in Higher Education (35, 326 - 339). Hobart Australia: Higher Education Research and Development Society of Australasia Inc. Retrieved from http://www.herdsa.org.au/?page id=2885

Tucker, B., Jones, S., \& Straker, L. (2008) Online student evaluation improves Course Experience Questionnaire results in a physiotherapy program, Higher Education Research \& Development, 27 (3), 281-296.

University Experience Survey. (2015). 2014 University Experience Survey National Report. Available at https://www.education.gov.au/university-experience-survey

van Os, W. (2010). Feedback from student ratings and the improvement of teaching performance. Paper presented at the EAIR 32nd Annual Forum in Valencia, Spain, 1 to 4 September 2010.

Watson, S. (2003). Closing the feedback loop: Ensuring effective action from student feedback. Tertiary Education Management, 9(2), 145-157.

Williams, J. (2002). Student satisfaction: a British model of effective use of student feedback in quality assurance and enhancement Paper presented at the 14th International Conference on Assessment and Quality in Higher Education, Vienna, 2427 July 2002

Williams, R. and Brennan, J. (2003). Collecting and using student feedback on quality and standards of learning and teaching in Higher Education (Bristol, Higher Education Funding Enhancing Student Feedback and Improvement Systems in Tertiary Education 99 Council for England). Available at http://oro.open.ac.uk/11876/4/6D7D5FC2 b.pdf

Williams, R., de Rassenfosse, G., Jensen, P. \& Marginson, S., (2013). The determinants of quality national higher education systems. Journal of Higher Education Policy and Management , 35 (6), 599-611. 